\title{
Fabrication Techniques of Micro/Nano Fibres based Nonwoven Composites: A Review
}

\section{Raghvendra KM ${ }^{1 *}$ and Sravanthi $\mathrm{L}^{2}$}

${ }^{1}$ International and Inter University Centre for Nanoscience and Nanotechnology, Mahatma Gandhi University, Kottayam, Kerala, India ${ }^{2}$ School of Chemical Sciences, Mahatma Gandhi University, Kottayam, Kerala, India

\begin{abstract}
Recently, nonwoven composites have been recognized to exhibit significant potential in several applications such as filtration, wound care, and biomedical devices. This is due to the fact that high performance nonwoven composites can be easily fabricated using cost effective as well as eco-friendly techniques. This review article presents the recent progress in fabrication techniques used for production of nonwoven composites using natural and synthetic polymers for textile application in particular. Different types of nonwoven web according to the production route are discussed in detail. In addition to this, various bonding techniques used for web bonding are also highlighted in this review.
\end{abstract}

Keywords: Nano/microfibers; Fabrication method; Nonwoven composites; Synthetic and natural polymers; Fabrication; 3D scaffold

\section{Introduction}

It is well known that textile items are utilized as a part of medical and healthcare sector in various forms like surgical covers, masks, caps, gowns, bed covers, blankets, pillowcases etc. Owing to the fact that there is necessity and increased demand for textile products in several applications, research activities are ever increasing in textile field for creation of new products. From the past decade, the term "nonwoven fabrics" has been admired extensively and it refers to fabric comprised of either continuous or discontinuous fibres in which the fibres are bonded together and embedded in a suitable polymer matrix. These nonwoven fabrics and composites are fabricated via application of chemical, mechanical or thermal treatments, which is in contrast to weaving process. Various adhesive bonding using both saturated and unsaturated polymers such as butadiene and acrylic acid, respectively can be used as the bonding agent of fibres. In addition to adhesives, bonding can also be achieved via mechanical interlocking mechanisms like needle punching as well as hydro entanglement and thermal technique i.e., appropriate application of heat [1]. Comparative analysis of woven and nonwoven fabrics is mentioned in Table 1 . The proper selection of technology for web creation, web bonding and finishing can help to accomplish the desired properties of nonwoven fabrics $[2,3]$. The extensive advancement of modern civilization limited the utilization of old nonwoven fabrics due to development of new product for the modern application driven by new processing technologies. At present, modern nonwoven innovation has expanded the utilization of nonwoven fabrics and development of nonwoven composites materials as alternatives old nonwoven fabrics for various applications [4-6]. The nonwoven fabrics composites are gaining prevalence day-by-day as substitute for metal or wood because of their light weight and unrivalled mechanical properties. In this way, nonwoven composites, which are multi-layer in nature laminates as well as 3D nonwoven fabrics, are being popularized because of their attracting chemical and physical properties including excellent mechanical strength, more prominent thermal stability, appearance, texture, high productivity, lower cost and disposability [7-9]. Among the textiles materials, nonwoven fabrics reinforced composites are drawn attention as the fastest-growing materials. In

Table 1: Comparative analysis of Fabrics production method with respect to production rate.

\begin{tabular}{|c|c|}
\hline Methods & Production rate of fabrics \\
\hline Nonwoven fabrics & Nearly $100 \mathrm{~meter} / \mathrm{min}$ \\
\hline Knitting & Nearly $2 \mathrm{~meter} / \mathrm{min}$ \\
\hline Weaving & Nearly $1 \mathrm{~meter} / \mathrm{min}$ \\
\hline
\end{tabular}

order to, fibre-reinforced polymer composite is described as material with two or more distinct physical phases, one of which is a fibrous phase. If the fibrous phase is natural /synthetic, it is called as natural/ synthetic fibres reinforced plastic composites (FRP), respectively. Fibres are strong, coarse and inflexible in nature, which makes it reasonable to concern as fortifying material in the composite system. In the last few decades, various forms of synthetic/natural fibres are examined for utilization as reinforcement in composites system [10-20]. For example, synthetic fibres namely glass, rayon, aramid, nylon, carbon, and polyester are comprehensively utilized as reinforcement in polymer matrices [11,12]. However, these synthetic fibres are more expensive as they are obtained from non-renewable resources. At the same time, natural fibres derived from renewable resources such as wood sisal kenaf, pine apple, jute, banana and straw coir Palmyra and pineapple are well process favourable and less expensive for fabrics and composites system. The characteristics of natural fibres derived from plants are mainly dependent on type, age, region of plant as well as strategy used for extraction of fibres. This is evident from different characteristics exhibited by fibres such as coir, sisal, pineapple and palm. In case of coir fibres, the presence of central portion termed as "lacuna" can be seen which is responsible for the hard nature of these fibre materials. Another fibre extracted from leaves "sisal" is extremely strong in nature. Pineapple fibres are also extracted from leaf resources and they exhibit soft nature with rich cellulose content. Palm fibres exhibit hard nature and comparable multicellular structure like coir fibres [21]. AnhydroD-glucose represents the basic constituent of cellulose and it consists of three hydroxyl groups. These groups are responsible for formation of intramolecular hydrogen bonding with in cellulose structure and with other hydroxyl groups present in the moisture content of air [22]. This is the reason behind the high content of moisture present in fibres derived from plants. Therefore, fibres derived from plants exhibit hydrophilic properties and vary in moisture content by $\sim 8-13 \%$ [23]. A broad research on fibres reinforced polymer composites using nonwoven

*Corresponding author: Raghvendra KM, International and Inter University Centre for Nanoscience and Nanotechnology, Mahatma Gandhi University, Kottayam, Kerala, India, Tel: +917034383435; E-mail: raghvendramishra4489@gmail.com

Received December 03, 2016; Accepted December 25, 2016; Published January 02, 2017

Citation: Raghvendra KM, Sravanthi L (2017) Fabrication Techniques of Micro/ Nano Fibres based Nonwoven Composites: A Review. Mod Chem Appl 5: 206. doi: 10.4172/2329-6798.1000206

Copyright: () 2017 Raghvendra KM, et al. This is an open-access article distributed under the terms of the Creative Commons Attribution License, which permits unrestricted use, distribution, and reproduction in any medium, provided the original author and source are credited. 
technology has helped in developing peculiar products. Through this technology, it is possible to change the size of the fibres and bonding between fibres can be possible via pressing. All such modifications can bring essential structural changes in the fibres and the degree of these structural changes is in turn dependent on handling parameters such as fibre introduction and fibre orientation [24,25]. The physical characteristics of the fabrics and composites are usually dependent on web geometry. However, appropriate web geometry can be obtained by particular route of web production. Interestingly, web geometry is in turn dependent on fibre shape and direction. Hence, addition of fibres with appropriate diameter and length in the polymer matrix is a viable approach to influence the property of web. Industry has implemented the manufacturing of micro/nano fibres reinforced composites because of their extensive demand in textile applications. The manufacturing techniques used for fabrication of composites include drawing technique, turbulent forming method, melt spinning, sheath-core spinning, flash-spinning, solution flash-spinning, emulsion-spinning, jet-spinning and conjugate-spinning. Techniques such as electro spinning, force spinning, melt blowing, biocomponent spinning and flash-spinning are used for fabrication of nanofibres. The main aim of this review paper is to summarize the fabrication methods used for production of novel class of micro/nano fibrillar nonwoven composites for textile applications. Different classifications of nonwoven web according to their production route along with web bonding techniques are also addressed.

\section{Nonwoven composites}

Composites are a novel class of high-performance engineering materials, which contains two phases i.e., continuous phase called as matrix, and dispersed phase named as reinforcement is tightly held by the matrix phase. The characteristics of the composites are dependent on interfacial adhesion (interaction), relative amounts of both constituent (matrix and dispersed phase) and morphology of dispersed and so on. The incorporation of fillers or reinforcements is employed to enhance the physical and mechanical properties of composites, according to dimension of dispersed phase, the composites are termed as macro, micro or nanocomposites. The dimension of these dispersed phases greatly affects the final properties of types of (nano/micro) composite materials. A good interfacial characteristic of composites can offer better performance. The existence of excellent interfacial bonding among reinforcement and matrix leads to build the load transfer mechanism from matrix to reinforcement phase, which can enhance tensile properties of composites. On the other hand, poor interfacial adhesion can increase energy dissipation through interface, and poor interfacial adhesion can decrease the tensile strength due to pulling mechanism of fibres from matrix, which can be observed by microscope techniques. As earlier mentioned, macro/micro/nanocomposites are defined by the microstructure of reinforcements or dispersed phase that means at least one dimension of fillers belongs to the micro or nano range. Initially, carbon, aramids and glass fibres with high modulus and strength have been the most frequently used in composites system for various applications. At present, reinforcement of micro/nanofibres in the polymer matrices is the recent trend for making high performance composites. In this manner, micro/nanofibres based nonwoven composites are being used as key materials for the textile industries. The nonwoven composites refer to the combinations of fibre webs or the resultant fibres embedded into another web, which means after the web formation step, the fibres and the plastic are bonded together by consolidation (melting of matrix web or bonding) process to form the final nonwoven composite. The steps involved in fabrication of nonwoven composites are shown in Figures 1 and 2.

\section{Macro/micro/nano fibres}

In general, there is no accepted definition for fibres. However, the term is related to linear density of the fibre in dtex. Fibres in the 1.0 dtex range are defined as conventional fibres. When the linear density of fibres is found to be in the range of 0.3 to $1 \mathrm{dtex}$, then such type of fibres are characterized as microfibres. The super microfibres refer to the fibres with less than 0.3 dtex. Microfibres can be utilized alone or in blends and exhibit the significant potential for textile application which is due to their conceivably more prominent properties and functionality. Moreover, fibres with linear density approximately 0.01 dtex are defined as nanofibres. Numerous types of polymers can be processed into nanofibres with the diameter range 50 to $1000 \mathrm{~nm}$. The characteristic features of nanofibres include high surface area, excellent mechanical properties and size ranging from 50-1000 nm [26]. Figure 3 shows the difference between conventional, micro and nanofibres as a function of fibre diameter. From the figure, it can be seen that the diameter of conventional fibres is greater than $10 \mu \mathrm{m}$. Decrement in terms of diameter are known to show impact on surface area, chemical, mechanical and thermal characteristics of fibres. All these factors in turn affect the fibre-matrix interaction and properties of composites. At present, the synthetic as well as natural micro/nanofibres are utilized as reinforcements in several polymer matrices such as polycaprolactone,

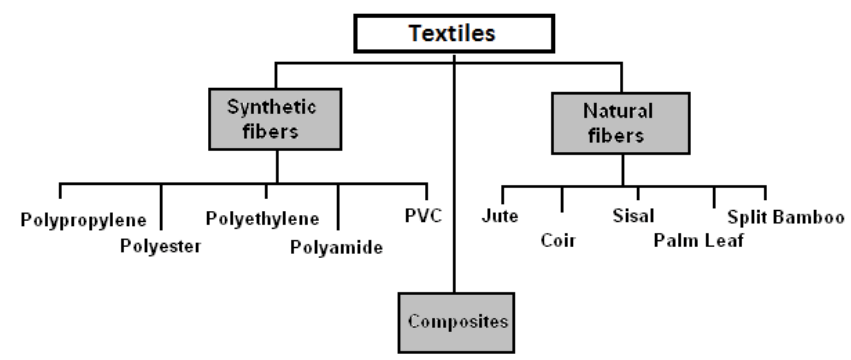

Figure 1: Classification of Fibres.

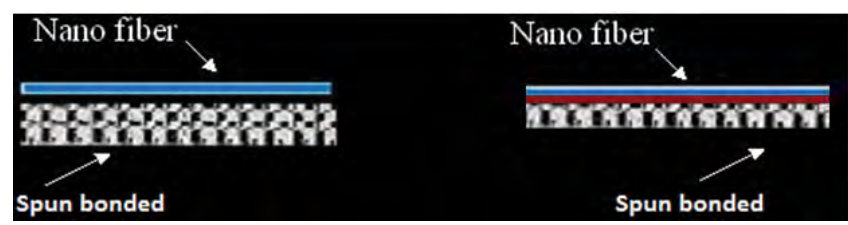

Figure 2: Fabrication steps for nonwoven composites.

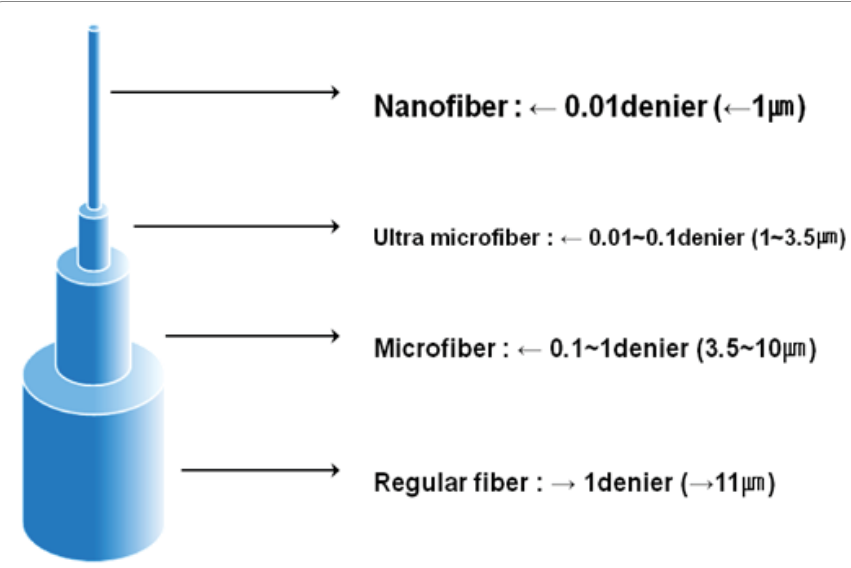

Figure 3: Comparison of diameter for conventional, micro and nanofibers. 
poly (lactic acid), nylon and acrylic acid [27]. It is conceivable to fabricate these ultrathin micro/nanofibres nonwoven fabrics composites by utilizing the micro and nanotechnology concept. Execution of this concept for fabrication of nonwoven fabrics can improve the properties of fabrics/composites in comparison with conventional fabrics/ composites. This is due to lightweight, high density, chemical, thermal stability, excellent wettability, and mechanical properties (high modulus and strength) of micro/nano fibres reinforced in polymer matrix [28].

\section{Surface fictionalization of fibres by plasma technique}

The final properties of fabrics and composites are described by the nature of the fibres used as reinforcement. Surface modification of fibres is employed to improve the functionality characteristics of fibres such as absorbance, hydrophobicity, wettability, matrix and fibers adhesion, these properties are enhanced by the modification of fibres through different functional group. Nowadays, various types of surface modification techniques are being applied such as low temperature plasma treatment, corona discharge sputtering. These treatments are cost and energy effective tenement. Figure 4 shows the plasma treatment process for surface modification of fibres. During such treatment, the reactive species of plasma interact with outer surface of fibres without affecting the bulk properties of fibres. Plasma is a fourth state of matter, which comprises a mixture of partially or fully ionized gas, free electrons, and chemically reactive radicals $[29,30]$. After plasma treatment, fibres exhibit the presence of $-\mathrm{OH},-\mathrm{NH}_{2}$ and $-\mathrm{COOH}$ functional moieties on the outer surface of fibres. These function group and reactive species have ability to alter the polarity, adhesion, and wettability properties of fibres. Low temperature plasma treatment is useful to change the surface energy and functionalise the fiber surface and polymeric materials by using the excited molecule, ion, free radicals etc. Low temperature have gained lot of interest for improving the crystallisation and cross linking, chemical modification, etching, polymerisation, free radical formation, chemical implantation, hydrophilicity and hydrophobicity and adhesive properties of polymer and fibre surface [31]. Sputtering alter the surface roughness, adhesion by roughness (mechanical interlocking), reflection of light (decrease the light reflection) Chemical modification is used to provide functional group, and it can alter surface energy and surface roughness of polymers and fibres Coupling agent and grafting are applied to change the molecular layer, surface energy. UV radiation is used to provide functional group and change in surface energy. Plasma polymerisation is used for molecular layer, surface energy and generates the free radical. Ion beam is applied for functional group, molecular layer, cross-linking and surface free energy.

\section{Effect of surface modification on polymer and fibre perfor- mance}

Surface modification can alter the surface functional group, cross-

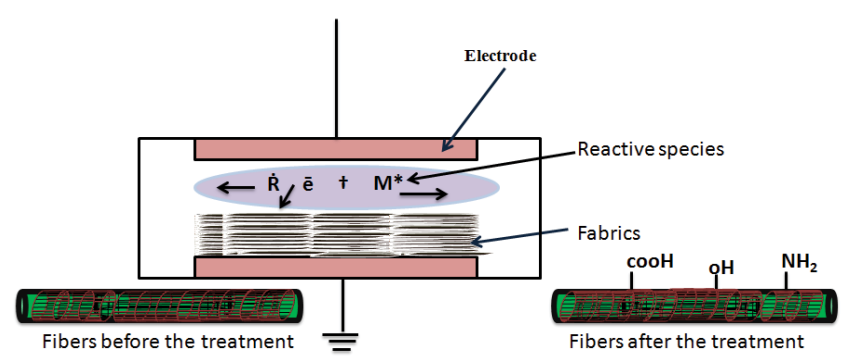

Figure 4: Plasma treatment process for surface modification of fibres. linking, free radical, crystallization, implantation, etching grafting. It changes the surface properties such as wear resistance, porosity, wetting, adhesion, surface tension, refractance, transmittance and reflectance, adhesion, medical compatibility.

\section{Nonwoven fabrics}

Traditional textile fabrics are produced by interlacing two or more yarn sets at right angles on a loom, or by knitting. Yarns are consisted fiber or filament bundles held together by twist or entanglement, it is intermediate product of fabrics- creating process. Nonwoven is similar to woven or knitted fabric, but there is some difference between woven and nonwoven fabrics, in the case of woven, fibres are changed into a planar structure and interlocked to form a porous sheet with some degree of flexibility through knitted, tufted stitch bonded incorporating binding yarns or filaments, or felted by wet milling. However, web or bats are fabricated by directionally or randomly oriented fibers, bonded through friction or cohesion or adhesion. Web bonding can be done by the applying an adhesive, Thermally fusing the fibers or filaments to each other or to the other meltable fibers or powders, Fusing fibers via first dissolving, and then resolidifying their surfaces, Creating physical tangles or tuft among the fibers, Stitching the fibers or filaments in place. Moreover, nonwovens consists adapting garneting, carding, and aerodynamic fiber handling methods to place textile fibres into preferentially oriented webs. In the case of nonwoven fabrics, the Fabrics are reveled to as dry laid nonwovens and carry terms such as "garnetted", "carded", and "air laid". In order to further explanation, nonwoven fabrics consist of millions of individual fibres, in which fibres produce a web like structure and finally bond together by various bonding technique. Nonwoven fabrics can be classified into different types based on certain factors involved in web manufacturing process such as production route and type of raw materials used for production of fabrics. Figure 4 shows the different classification of nonwoven fabrics. With respect to production route of web, nonwoven fabrics can be categorized into wet, dry and spun bonded fabrics. Taking into account the type of raw materials, nonwoven fabrics are classified as staple fibre and filament. Based on the end use applications, nonwoven fabrics can be divided into durable, semi-durable and disposal types. Depending on the nature of the nonwoven fabrics, it is classified as flame retardant, water replant and water permeable fabrics. All nonwoven fabrics are produced by anisotropic or isotropic oriented fibrous web and the density of nonwoven fabrics refers to the type of fibers and structure. The technological process and classification of non-woven fabrics are mentioned in Figures 5 and 6 [31-35].

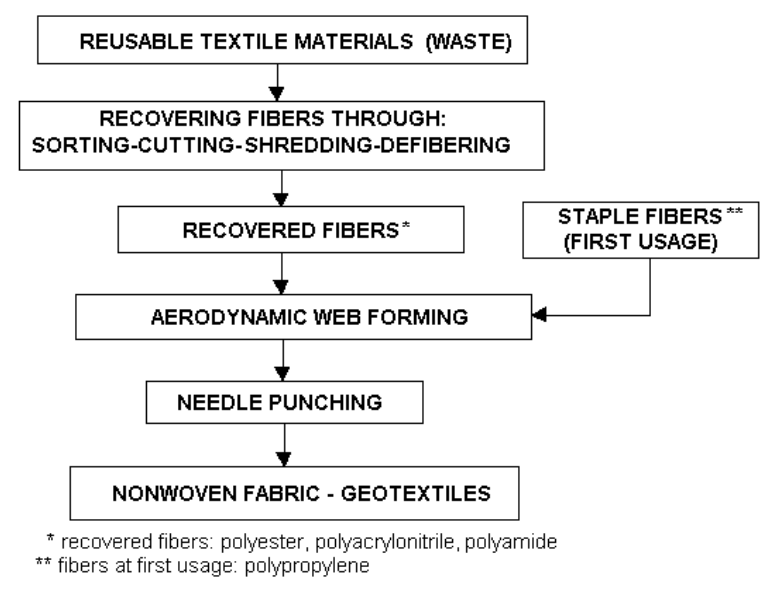

Figure 5: Technological process for nonwovens textile. 


\section{Properties of nonwoven fabrics based various fibres}

Polyester fabrics shows good recovery, excellent weight strength, excellent elasticity, good heat setting properties. However, it has more pilling tendency. Polyamide fabrics It offers good resistance to soiling, good wet strength, excellent chemical resistance, good elasticity, and excellent heat susceptibility. However, it is poor in handling, high pilling tendency and costly. Viscose filament (Rayon Filament) It shows good strength, easy cleaning, less or negligible pilling tendency, cheap in cost. Low wet strength, difficult in handling and poor abrasion resistance are major drawback. Polyacrylonitrile It offer good recovery, excellent chemical resistance, excellent moisture resistance, but it is in costly in price and show pilling off tendency. Acetate filament: It has good recovery, easy bonding capability, low abrasion and wear resistance, but it is cheap in cost. Cotton: It has good abrasion, good wet strength, easy in handling, excellent absorption capacity and low in cost. It shows non-elastic recovery, poor uniformity in fiber, poor resistance to soiling. Wool it offers a good absorption capacity, high elasticity, fast recovery, high tendency to pilling off, high shrinkage, low strength, low abrasion resistance.

\section{Application of nonwoven fabrics}

- Agriculture Crop Covers, Weed control fabrics, Protection of products, Root bags, Nursery over wintering, Containers etc.

- Clothing Shoe components, Bra and shoulder padding, Gloves, Handbag parts, Geotextiles etc.

- Soil stabilization, Pond liners, Sedimentation and erosion, Golf and tennis courts, Road and railroad beds, Drainage, Construction Acoustical ceilings, Pipe wrap, Insulation, Roofing and tile underlayment etc.

- Automotive Cover slip sheets, Transmission oil filters, Door trim panel padding and carpet, Hood silencer pads, Dash insulators, Floor covers, Front and back liners, Wheelhouse covers, etc.

- Household Aprons, Fabric softener sheets, napkins, Wipes, wet, dry polishing, Ironing board pads, Tablecloths, Tea and coffee bags, Towels etc.

- Academic and Office Floppy disk liners, Pen nibs, Maps, signs, pennants, Book covers etc. Medical and Lab Shoe covers, Orthopedic padding, Dental bibs, Sterile packaging, Bed linen, underpads, Electrodes, Examination gowns, Dialyzers,

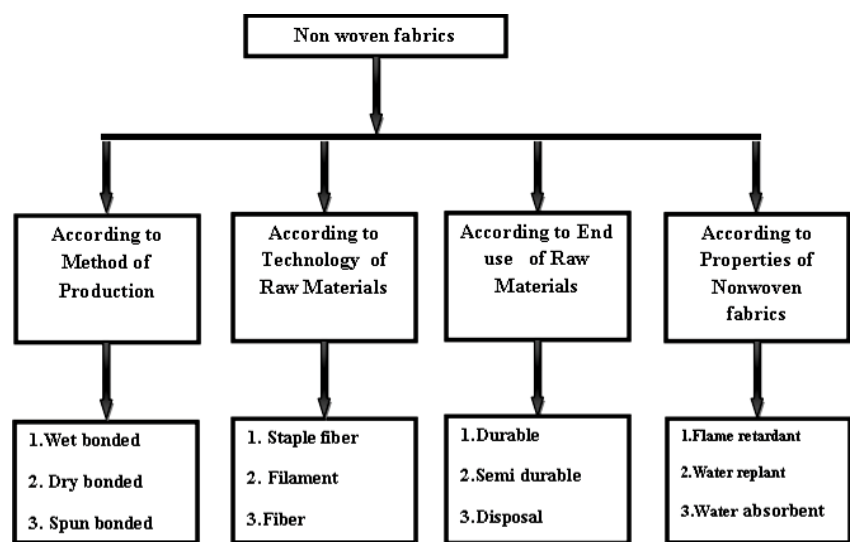

Figure 6: Classification of nonwoven fabrics according method, raw materials and properties.
Transdermal drug delivery etc.

- Military Coated fabrics, Semiconductor polishing pads, Wipers, Air conditioning filters, Army clothing, Cable insulation, Sorbents, Flame barriers, Packaging, Conveyor belts, Noise absorbent felt etc.

\section{Types of nonwoven web}

There are various kinds of web, which can be utilized for fabrics production. As indicated by the production technique, nonwoven webs are characterized into different types such as staple fibre and spun melt webs which are further classified into dry-laid, wet-laid webs, spun laid, melt blown and flash spun webs. Production line and various types of nonwoven webs according to production route are shown in Figures 7 and 8. A comparison between different web forming process is mentioned in Table 2.

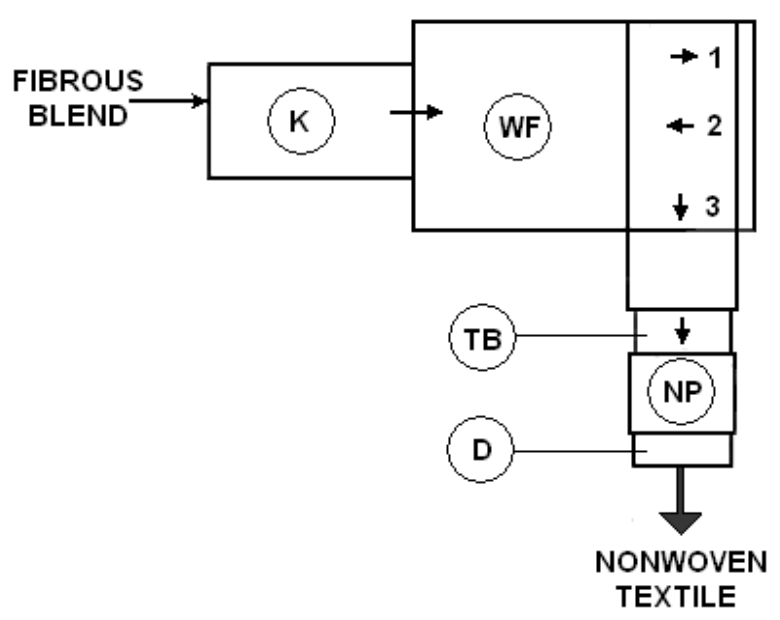

Figure 7: Production line of nonwoven textile [K - Carding machine, WF - Drylaid web formation machine, TB - Transportation belt for fibrous layer, NP Needle punching machine, D - Nonwoven delivery (rolling device)].

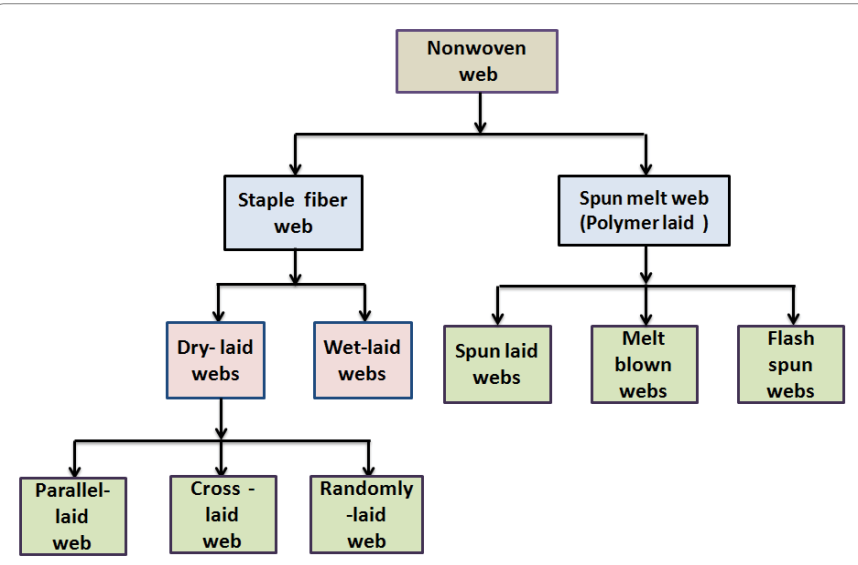

Figure 8: Different types of the nonwoven web based on production route.

Table 2: Comparison between Webs forming process.

\begin{tabular}{|c|c|c|c|}
\hline Process & Technology & $\begin{array}{c}\text { Relative } \\
\text { production rate }\end{array}$ & $\begin{array}{c}\text { As per market } \\
\text { (\%) }\end{array}$ \\
\hline Wet laid web & Wet laid web & High & Low \\
\hline $\begin{array}{c}\text { Spun melt web } \\
\text { (polymer extrusion) }\end{array}$ & $\begin{array}{c}\text { Spun laid, melt } \\
\text { blow }\end{array}$ & Medium & Medium \\
\hline Dry laid web & Carding, Air laid & Low & High \\
\hline
\end{tabular}




\section{Wet-laid web}

In this approach, both natural and synthetic fibres can be used to produce wet-laid web. For production of wet-laid web, short staple fibres are generally preferable. The schematic representation of wetlaid web is shown in Figure 9. In this process, the fibres to be utilized are blended with water to form water /fibre slurry. Then, the slurry is deposited on the forming belt. Finally, the excess water is removed from fibre to produce uniform sheet (web). With due course of further processing, sheets are bonded and dried. The flow chart for preparation of fabrics through wet-laid process is shown in Figure 10. The widely used bonding materials for wet-laid process include vinyl chlorides, styrene/butadiene and polyacrylate. All these crosslinkable synthetic polymers are dispersed in water and used in water based emulsion form during the wet-laid process for fabrication of nonwoven fabrics. However, the degree of fineness (length and thickness of the fibre), stiffness of the fibre in an aqueous medium, wettability, cutting quality of the fibre are the main factor, and dispersion behaviour of a fibre in aqueous medium largely depends on it [36-38].

\section{Significance of wet laid process}

It is modified version of papermaking process; It is used to produce structures with textile-fabric characteristics, primarily flexibility and strength; In the roll, good industry $5-10 \%$ nonwoven is made by wet laid process. This process offer high production rate (up to $1000 \mathrm{~m} / \mathrm{min}$ ); Any natural or synthetic long fibre can be used; Cotton linters, manila hemp and cellulose staple fibre are frequently used fibre in wet laid process. Waterproof sheeting for roofs, Shingling, Separators, Filters, Reinforcement material for plastics Surgical clothing, Bed-linen, Table cloths, Household cloth, face cloth are some example of nonwoven fabrics based on wet laid process. Wet laid based web structures are stiffer, Flexible in weight, Control of fibre orientation during web formation than dry laid web, but weaker than dry laid web structure. Synthetic fibre paper, dust filters, filters for liquids, waterproof sheeting roof, shingling, separators, filters, surgical, bed-linen, table cloths are the based on wet laid process.

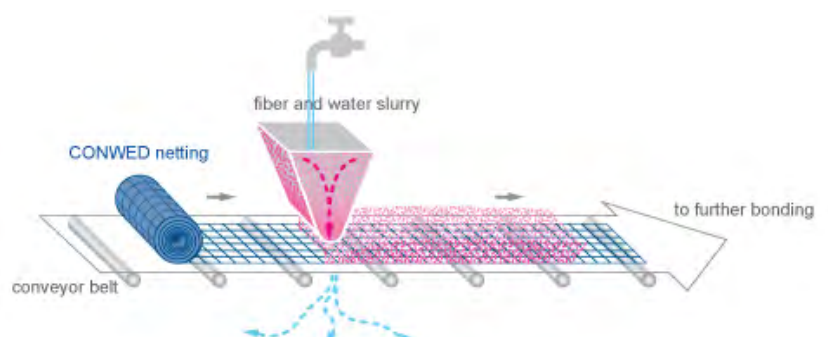

Figure 9: Schematic representation for wet-laid web process.

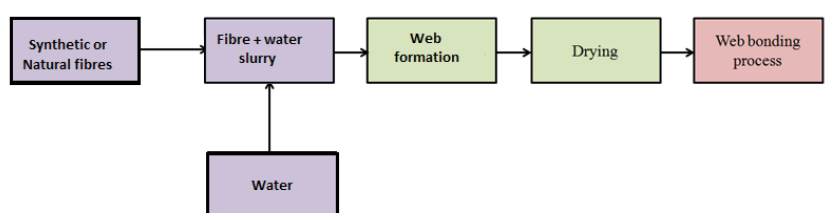

Figure 10: Flow chart for preparation of nonwoven fabrics through wet laid web process.

\section{Dry-laid web}

Fibrous web are generated from, performance of product is defined by the properties of the web, web geometry, web formation method, fibre diameter, fibre length, web weight, chemical and mechanical properties of the polymer influence the properties of web, stable length fibre based web is produced by the carding process. Dry laid web process includes two strategies i.e., carding or Garnetting (mechanical web formation process) or air laid (Aerodynamic web generation) to convert staple fibres into web. The carding process utilizes long fibres whereas the air laid process uses short fibres for their conversion into web. In Air laid process, fibres are introduced into air stream in order to structure a web that consists of randomly distributed fibres [39]. The schematic representation of dry laid web process is shown in Figure 11.

Staple fibre: Staple fibres refer to bunch of synthetic (man-made fibres such as rayon, nylon, acrylic and polyester or natural (fibres produced by plants such as cotton (seed hairs), flax and hemp (stem or bast fibres), sisal (leaf fibres), coconut (husk fibres), cellulosic fibre e.g., cotton and linen and animals or protein fibre such as wool, hair and secretions ex. silk) short fibres which have a standardized length in the range of 1.2 to $20 \mathrm{~cm}$. Polypropylene, nylon, polyester, glass, jute, wool, silk, flax, cotton can be utilized as raw materials for staple fibres [39]. In order to, fibres are classified as short or long according to length of fibres. The short length fibres are named as staple fibres (length is measured either in inches or centimetres) and the long fibres are called as filaments and length is measured in yards/ meters [40]. Compression between filament and staple fibers are shown in Figure 12 and Table 2.

Carding process: Carding involves mechanical process that individualizes a small bunch of fibres into single fibre by bale machine. The individualized fibres are then transferred into hopper for blending and then conveyed to further processing steps by rotational as well as aerodynamic forces through which web is created [41]. The carding

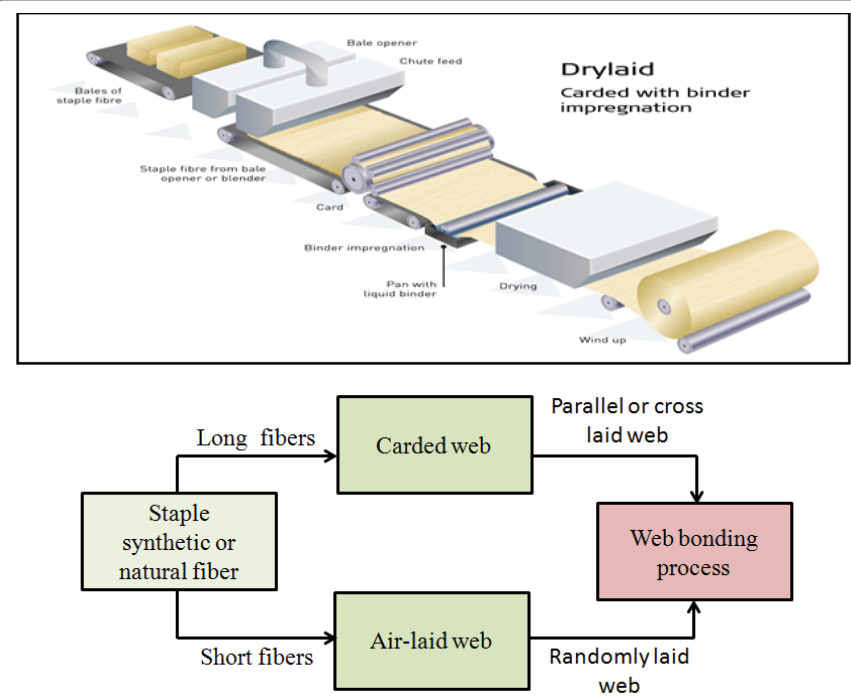

Figure 11: Schematic representation of dry laid web process (carded).
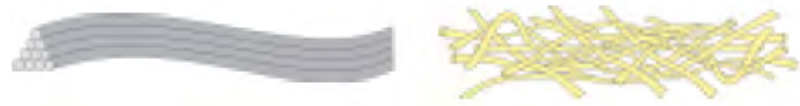

Figure 12: Schematic representation of filament fibers (left), staple fibers (right). 
machine consists of major drums, the taker-in, cylinder and doffer drums. Using this process, two types of web can be created (i) parallel laid and (ii) cross laid. In case of parallel laid web, fibres or filaments are laid in parallel directions to the machine traverse. The parallel laid web exhibit attractive mechanical properties such as good tensile strength, low elongation-at-break and low tear strength [42]. However, in random laid web process, the fibres are laid in random directions. Cross laying is a fibre web forming process in which the resultant web is in the form of multi-layered form. In this process, the fibres are laid on a conveyor belt which is travelling at right angles to the direction of fibres. In case of cross laid web process, the resultant web is subjected to one or more bonding techniques in order to achieve fabric integrity. The schematic representation of carding process is shown in Figure 13.

Significance of carding process: Carding process has several advantage, some of the advantage are: It is used to straighten the fibres; It is opening, cleaning, removing short fibres process; it is beneficial for generating uniform fibrous strands; It is used converting the individual fibres into a uniform fibrous web;It can produce randomly and little oriented fibre structure; Carding show high production rate; Carding is also used to blend various kinds of fibre together to produce a nonwoven [43].

Air laid process: Air laid process is nonwoven web forming process in which the web of fibres is produced by the dispersion of fibres ranging from 1-4 $\mathrm{mm}$. The schematic representation of air laid web process is shown in Figure 14. Initially, the fibres are dispersed into a fast moving air stream and then transported towards the moving belt or perforated drum under pressure or vacuum. Finally, the fibres condense on the surface of moving belt or drum in order to create web [44].

Significance of air laid process: This process is also employed for opening, cleaning, removing short fibres; Fibres are deposited on a moving forming screen or rotating perforated cylinder in random orientated manner. This process is used to produce lightweight and heavy high loft nonwovens. This is used to fabricate the composites in easy manner. This process is very helpful to produce various densities such as very low and very high with diverse materials. By this process,

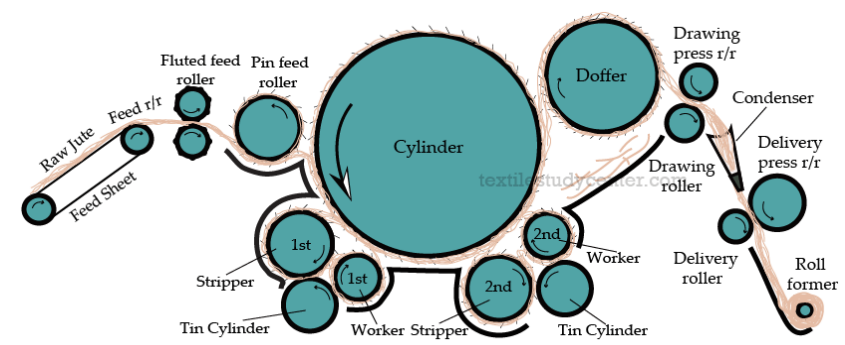

Figure 13: Schematic representation of carding process.

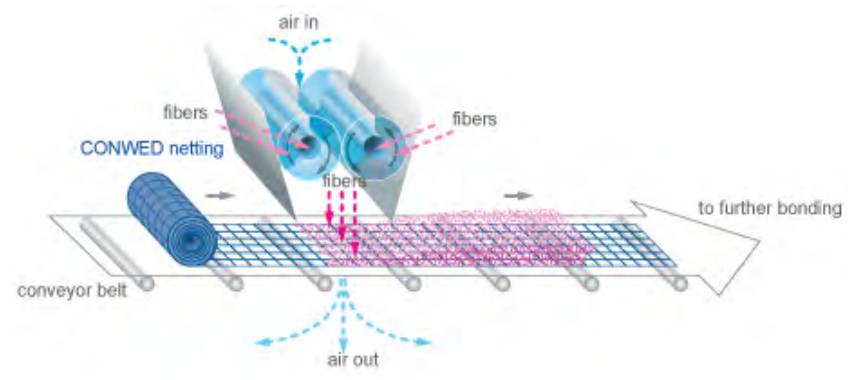

Figure 14: Schematic representation for air-laid web preparation. stiffness and softness is easily controllable, but capital cost of this process is high.

\section{Spun melt web}

This technology is used to generate web with fibres of micron size diameter. Three different types of spun melt web technique are employed to attain nonwoven fibres web of thermoplastic polymers. The schematic process flow chart of spun melt web process is shown in Figure 15.

Spun laid web: This particular procedure which is also called spun bond web technique is carried out in two stages (i) melting of polymer granules and extrusion of molten polymer via extrusion technique for generation of polymer strands; subsequently, strands are drawn by cold or hot drawing to get continuous fibre, and (ii) deposition of the resultant continuous fibres on a conveyor in order to obtain uniform web. The nonwoven fabrics produced by this technique offers greater strength and less flexibility $[45,46]$. The schematic representation of spun laid web process can be seen from Figure 16.

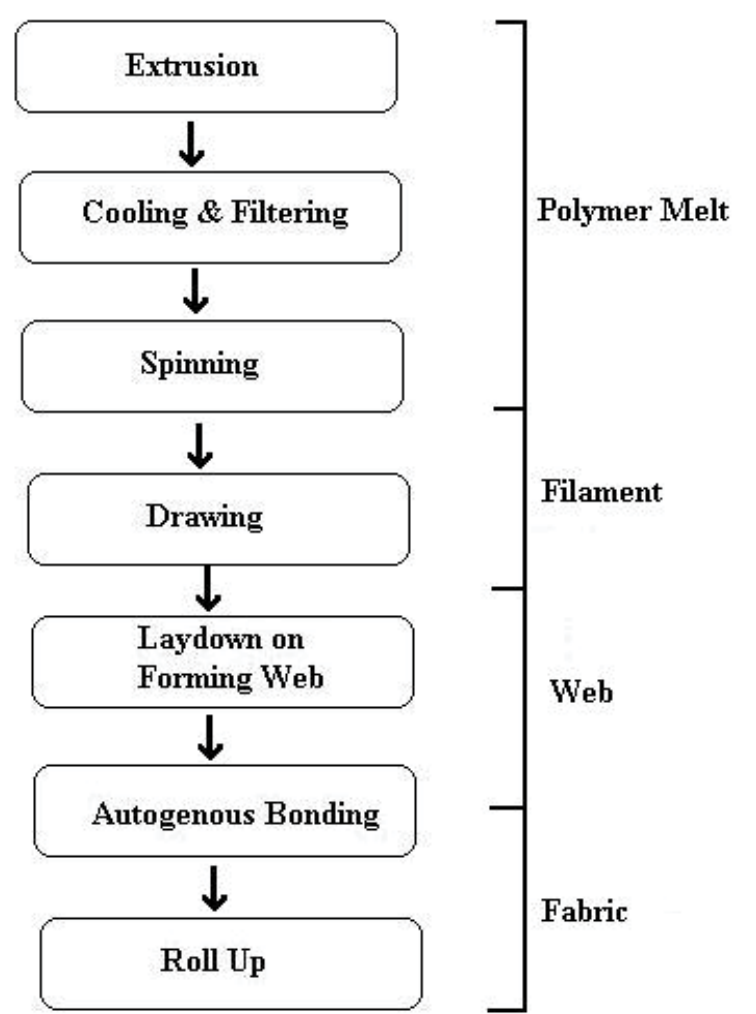

Figure 15: Schematic representation for spun melt web preparation.

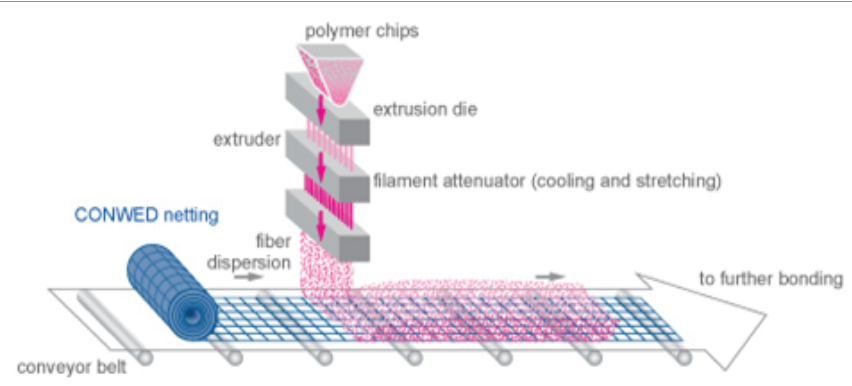

Figure 16: Schematic representation of spun laid web process. 
Significance of spun laid web: These types of web are new class of web, which properties of web is found in between paper and woven fabrics; The weight of webs increase with increasing the number of layers; Web thicknesses are in the range 0.2-1.5 mm. These types web show High strength-to-weight ratios compared to other nonwoven, woven, and knitted structures; and these webs offer High tear strength. This process is applied for getting nonwovens with greater strength, lightweight and flexible, but raw material flexibility is more limited. Spun bonded webs are frequently used for trim parts, trunk liners, interior door panel, and seat covers of automobile, erosion control, revestment protection, railroad beds stabilization, canal and reservoir lining protection, highway, and airfield black top cracking prevention, roofing in civil engineering, metal-core wrap, medical sterile packaging, floppy disk liners, high performance envelopes and stationery products.

\section{Melt blown web}

In melt blown web forming process, polymer granules which are low viscous in nature and molten polymer granules are drawn by a high velocity air stream through nozzle tip (extruder die). The drawing polymer is performed by drag force of air stream and gets converted into microfibres. The fine fibres formed are then solidified on the collector as web. The air temperature is fixed equal or slightly higher than the melting point of the polymer [47]. The schematic representation of melt blow web preparation procedure is shown in Figure 17.

Significance of melt blown web: Random fibre orientation, lower to moderate web strength, fine fibre diameter, high surface area for good insulation and filtration are main characteristics of melt blow web;Isotropic products are obtained through the melt blow process.

Flash spun web: Flash spun web is produced by three steps which include (i) dissolution of polymer in a solvent, (ii) spraying process of suspended polymer into low pressure vessel and (iii) flashing of solvent takes place due to which web containing cloud like fibres is generated.

\section{Other Methods for Production of Nonwoven Fabrics}

\section{Electro spinning process}

The electrospinning is broadly used to produce micro/nanofibres. In the electrospinning process, polymer dissolved in appropriate solvent is injected through a syringe. After the critical voltage is arrived, imbalance in charge created by electrical potential tends to overcome the surface tension of the polymer solution. Thereafter, a jet which is

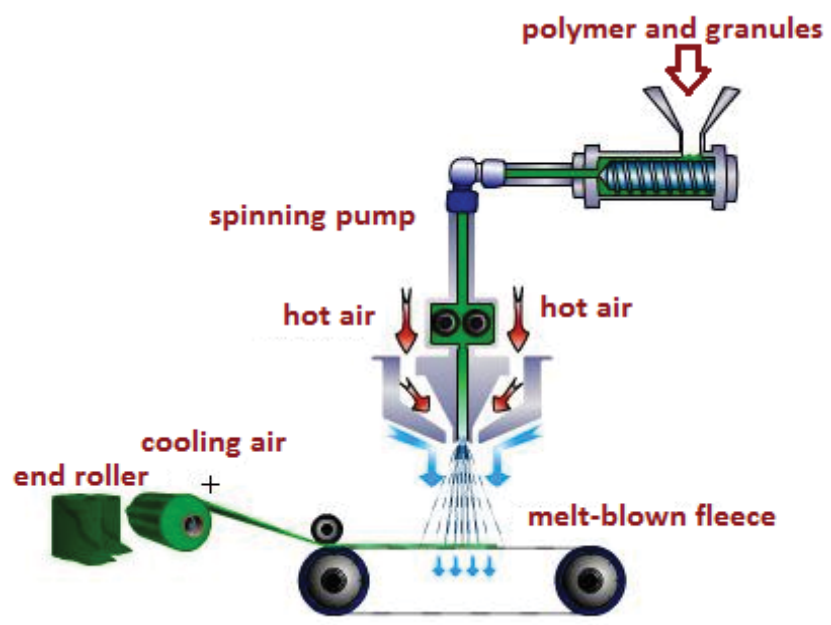

Figure 17: Schematic representation for melt blow web process. electrically charged moves towards the lower potential. By this interval of time, the solvent gets evaporated and generation of polymer fibres and fibres are collected on the stationary or rotating drum (lower potential). The distance between tip of syringe collection are fixed in the range of $15-30 \mathrm{~cm}$. Most of the nanofibres are produced by the electrospinning process [48]. The characteristics of fibres depend on the polymer type and processing condition. The principle of electrospinning is represented in Figure 18.

\section{Solvent for electro spinning process}

In the electrospinning process, suitable solvent are used to make polymer and solvent solution, and these solution are spun by the electrospinning machine. Table 3 indicates the list of polymer and related solvent for electrospinning. Nylon, polystyrene, polyacrylonitrile, polycarbonate, $\mathrm{PEO}, \mathrm{PET}$ and water-soluble polymers are used in electro spinning process for generating nanofibres, these nanofibres have excellent properties such as mechanical properties, high surface area and extremely high surface to weight ratio compared to conventional nonwovens. Nanofibres nonwoven is most use full for wide range of filtration applications due to their large surface area to mass, high pore volume, tight pore size, high density. Diameters of nanofibres are much smaller than single human hair, as shown in Figure 19.

\section{Significance of nanofibres through electro spinning}

Due to extremely high surface area of nano fibres and smaller micro pores than other above mention process, Nano fibres can be used filtering the submicron particles from air or water. Electrospinning process can give three or more time smaller fibre diameter than above mentioned techniques. Electro spun fibres are comparative lighter than

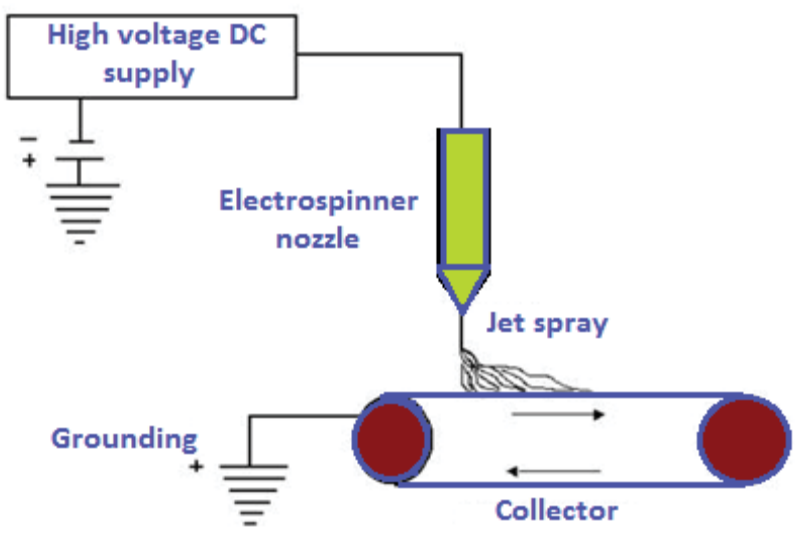

Figure 18: The principle of electro spinning process.

Table 3: List of Polymer and related solvent for electro spinning.

\begin{tabular}{|c|c|}
\hline Polymer & Solvent \\
\hline Polyimides & Phenol \\
\hline Polybenzimidazole & Dimethyl acetamide \\
\hline Polyramide & Sulfuric acid \\
\hline Polystyrene & DMF/Toluene \\
\hline PVA & Water \\
\hline PET & Trifluoroacetic acid/Dimethyl chloride \\
\hline Polyacrylonitrile & Dimethyl formaldehyde \\
\hline Nylon-6-co-polyamide & Formic acid \\
\hline Nylon 6 and nylon 66 & Formic Acid \\
\hline Polyolefin & Xylene \\
\hline PCL and PLA & Chloroform and Acetone \\
\hline
\end{tabular}


Citation: Raghvendra KM, Sravanthi L (2017) Fabrication Techniques of Micro/Nano Fibres based Nonwoven Composites: A Review. Mod Chem Appl 5: 206. doi: 10.4172/2329-6798.1000206

Page 8 of 11

other fibres; Nano fibres or webs are used for drug and gene delivery, artificial blood vessels, artificial organs, and medical facemasks, delivering medicines directly to internal tissues, because, as shown in Figure 18, diameter of fibre is much smaller than blood cell; large surface area-to-volume ratio of nano fibres offer more binding sites to cell membrane receptors and adsorption of serum proteins; Cost, health hazards, solvent vapour, packaging, shipping and handling of nano fibres are major issue.

\section{Nano/Microfibre hybrid process}

The hybrid web of micro and Nano fibres can be generated by combination of two processes such as electro spinning and melt blowing. Both the methods are carried out simultaneously and the resultant hybrid micro/nano fibre webs are collected on the rotating drum $[49,50]$. The principle of coupled melt blow and electrospinning process is represented in Figure 19.

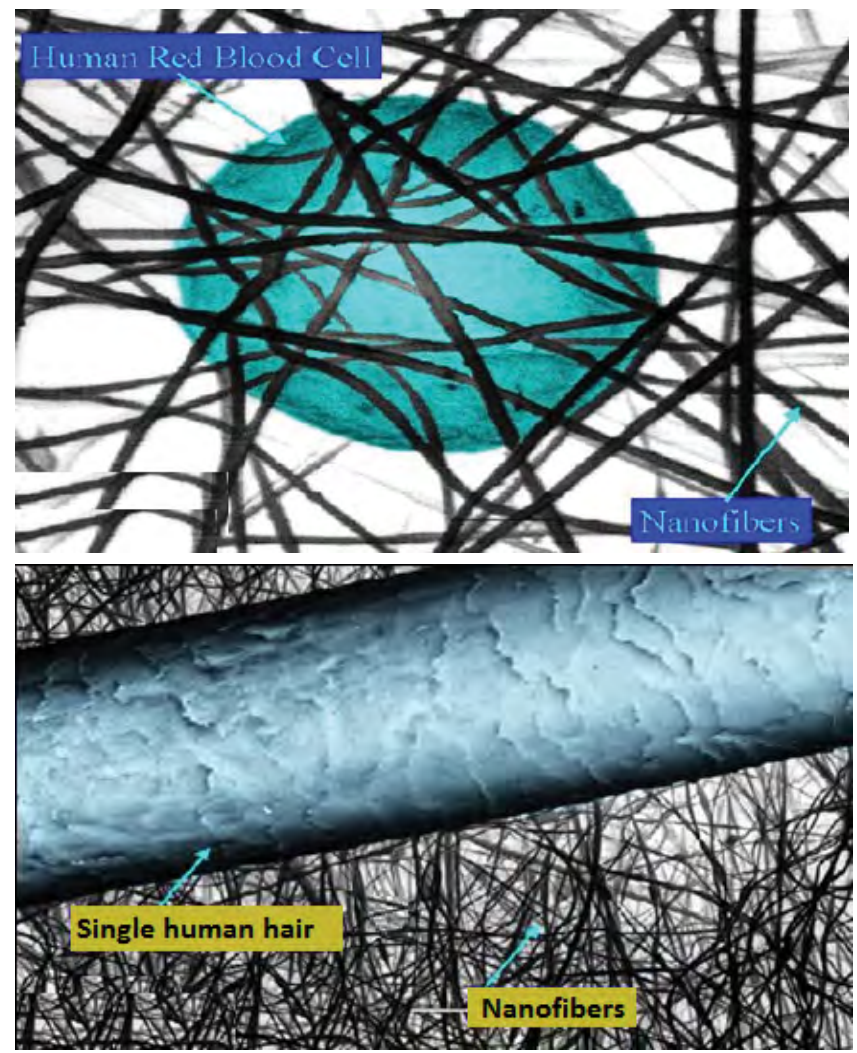

Figure 19: Comparative diameter analysis of human hair and nanofibers (left), comparison of red blood cell with nanofibres web (right).

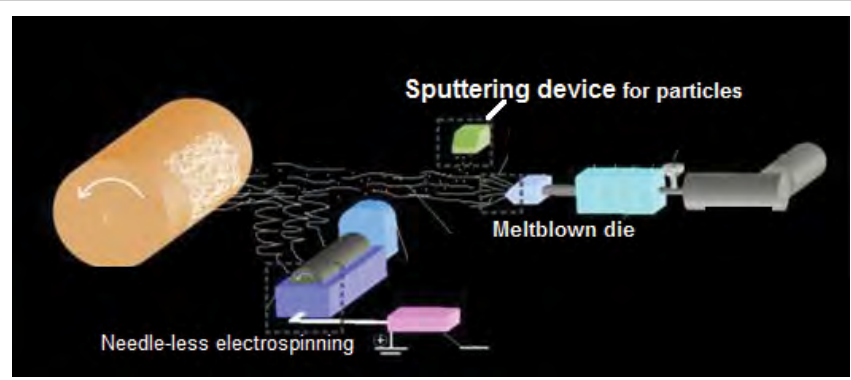

Figure 20: Coupled meltblown and electrospinning in-situ particles and polymer hybrid fiber web.

\section{Significance of nano/microfibre hybrid process}

Sufficient high surface properties and porous Structure can be obtained These hybrid fibers web can be used for bone substitutes, cell growth, and better adhesion.

\section{Fabrication of 3D nanofibres structure}

As everyone knows, 3D-thick shape, appropriate porosity, and size of porosity are important factor for designing the scaffolds, because, these parameter offer space for cell adhesion, spreading, migration and growth. Spinning can b employed for designing a 3D scaffold. Scheme of the fabrication procedure of $3 \mathrm{D}$ helical-designed electro spun scaffolds is shown in Figure 20.

\section{Air brushing process}

Air brushing method is also called as solution blow spinning or solution spraying. Figure 21 shows the preparation of nanofibres via air brushing technique [51,52]. This method is employed to fabricate polymer-based micro/nanofibres in which polymer solution are blown by compressed gas to fabricate nano fibres and subsequently collected onto wide range of collector [52-54]. Different shapes of collectors used for deposition of air brushed fibres can be seen from Figure 22

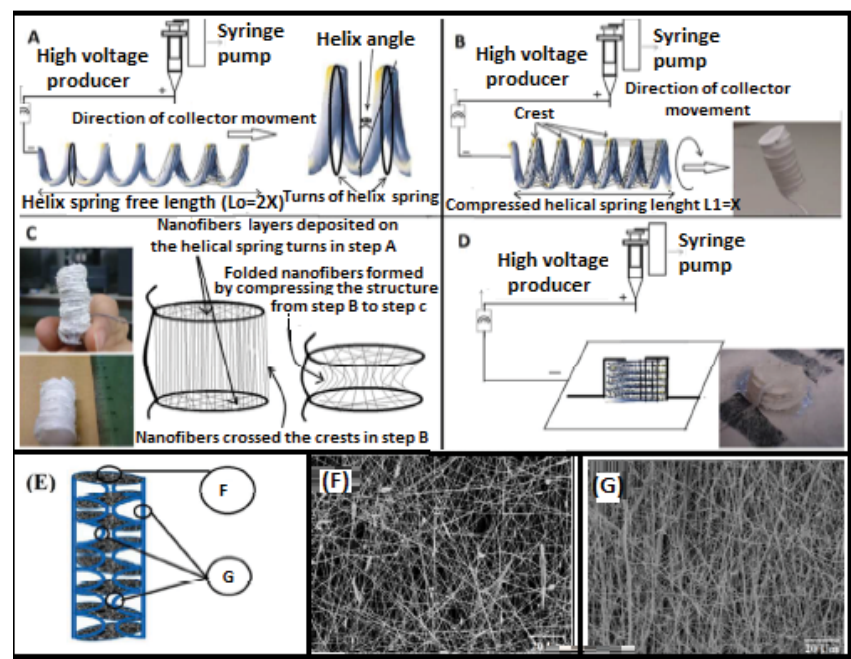

Figure 21: (A) First step: deposition of nanofibres on main turns of helical spring. (B) Second step: nanofibres deposition across the spring crests and covering the spring all around. (C) Third step: removal of the wire and compressing the nanofibres scaffold to a desired thickness. (D) Forth step molding the resultant cylindrical scaffold. (E): Scheme of the 3D electrospun structure generated on different regions of the helical spring collector: $F$ and $G$ refer to SEM images $F$ and $G$.

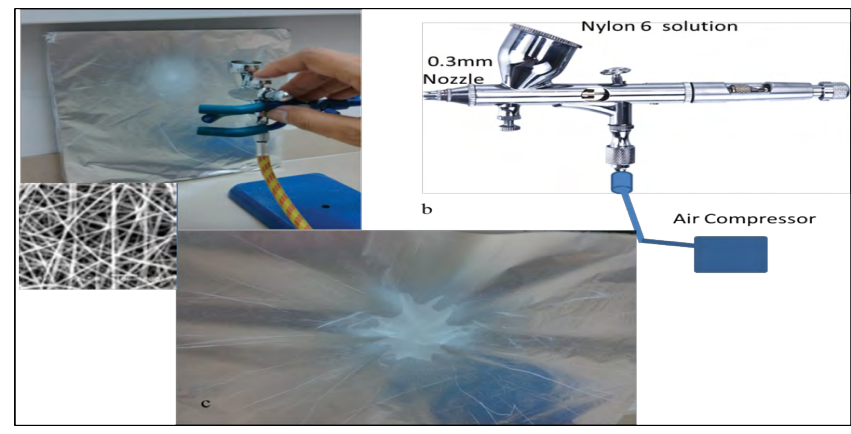

Figure 22: Preparation of nanofibres via air brushing technique. 
This procedure has several advantages over various other techniques which can extend its use in various areas and applications to create the financially worthy item. Interestingly, this procedure is more relevant for producing highly porous and lower modulus nano fibres at the high injection rates. In addition to this, air brushing procedure is practically identical and more secure than ordinary electrospinning process. This is because; manufacturing of fibres is possible without utilizing of any type of high voltage equipment [55-58]. At present, this technique is being used for fabrication of micro/nano webs [56-59]. However, only exceptionally limited work is carried out using this technique for fabrication of nonwoven fabrics.

\section{Magneto spinning}

Magneto spinning is a novel, simple and recent method employed for producing very large quantities of micro/nano fibres that can be embedded with a group of materials. Initially, small amount of ferromagnetic particles is added into polymer solution in order to get polymer embedded ferro fluid. In the presence of external magnetic field, nano fibres can be drawn out of polymeric material. The magneto spinning set-up is illustrated in Figure 23. The set-up consists of a permanent magnet which is then mounted on stage and located close to the needle present in the syringe filled with ferro fluid. Once the stage starts rotating, the magnet mounted on it also rotates which leads to the attraction of magnetic particles of ferro fluid by rotating magnet. As this process progresses, polymer is drawn into fibres. Once the solvent evaporates, micro/ nano fibres are collected $[60,61]$.

\section{Types of web bonding}

To improve the physical properties of web during production of nonwoven fabrics, web bonding and colonisation of web in polymer matrix is an important step. This is because; webs produced using several techniques other than spun laid web process exhibit poor physical properties. In order overcome this drawback, bonding actions which include (i) mechanical, (ii) chemical and (iii) thermal processes are used for bonding of web in order to produce the nonwoven fabrics or composites.

Mechanical bonding: In mechanical bonding process, web strength is attained by physical entanglement of fibres. The steps involved in mechanical bonding process are presented in Figure 24. Mechanical bonding can be carried by hydro-entanglement and needle punching process as explained below.

Hydro-entanglement: This process is particularly suitable for webs created by carding or wet laid process. Jets containing water at high pressure are used for mechanical entanglement of fibres. High pressure jets are found to have direct impact on the creation of web.

Needle punching: This process is applicable for wide range of fibre types. For entanglement of fibres, needles with special design are used. Such needles are subjected to continuous pushing and pulling process for production of entangled fibres.

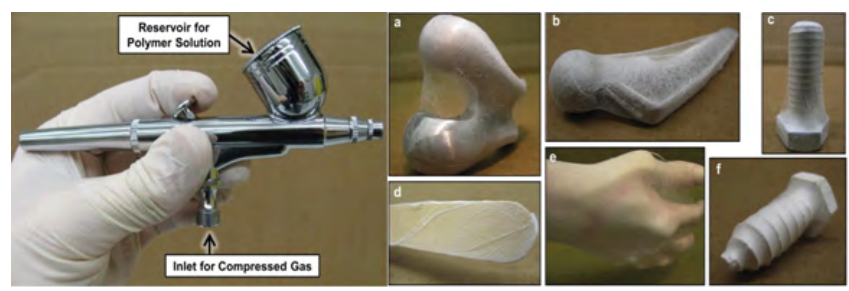

Figure 23: Deposition of Air brush nanofibres onto various irregular shapes.

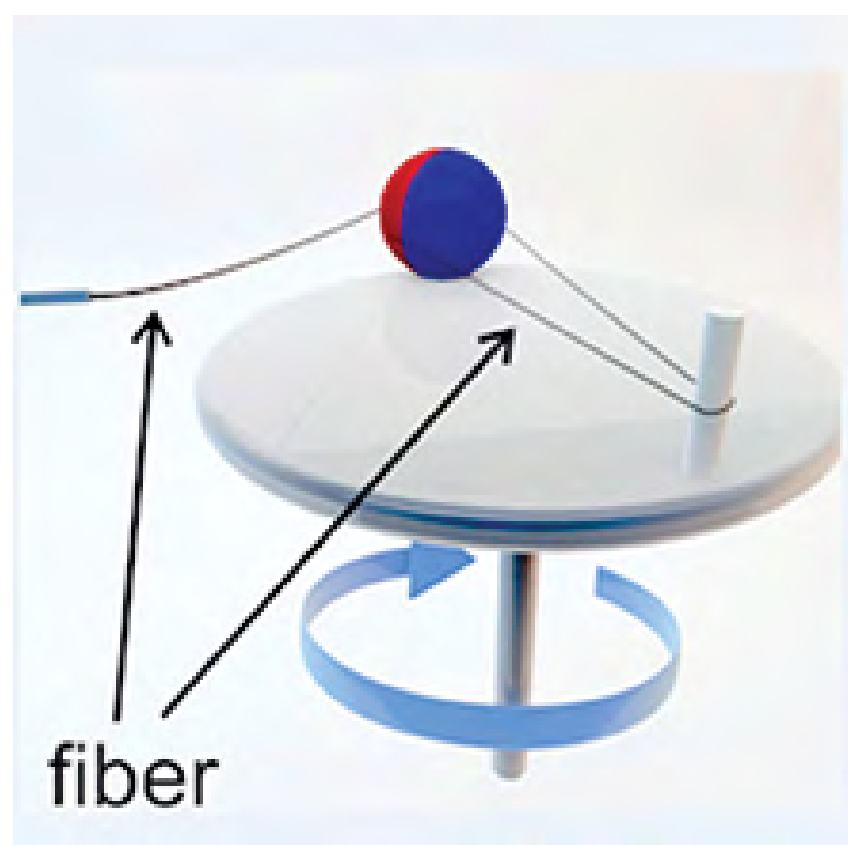

Figure 24: Set-up for magneto spinning process.

Chemical bonding: Chemical bonding is otherwise called to be adhesion bonding. The steps involved in chemical bonding process are shown in Figure 25. This type of bonding involves powdered adhesives, foam and organic solvent solutions, polymer and copolymer based binders such as styrene/butadiene as well as vinyl acetate ethylene copolymers as the most commonly used bonding agents for creation of web.

Thermal bonding: Thermal bonding is otherwise termed as cohesion bonding. The steps involved in thermal bonding process are shown in Figure 26. This type of bonding is completed under the application of heat. The two sub categories include (i) calendaring and (ii) air thermal bonding. This classification is based on the difference in melting point of matrix web materials. Temperature is applied to fuse the matrix web fibres. Hence, formation of bonding occurs between reinforced web and matrix web.

Finishing treatment for nonwoven fabrics: Finishing is a final step of nonwoven fabric preparation to make it ready for end use application. This step consists of several processes including slitting, cutting, folding, sewing or heat sealing. A series of steps involved in production of nonwoven fabrics is illustrated in Figures 27 and 28.

\section{Conclusions}

Combinations of various methods are described for production of nonwoven Nano/microfibre based fabric composites for textile application. All the techniques described in the current article emphasizes that high aspect ratio of the reinforced fibres plays an important role in determining the mechanical properties of the nonwoven fabrics. Based on the end use application of the fabrics, appropriate processing as well as bonding techniques can be selected. Modern techniques such as $3 \mathrm{D}$ scaffold, air brushing as well as magneto spinning for the fabrication of nonwoven micro/nano fibres based composites are also discussed. In summary, overall idea of recent progress in fabrication techniques used for making nonwoven composites suitable for textile application can be drawn from this review. 
Citation: Raghvendra KM, Sravanthi L (2017) Fabrication Techniques of Micro/Nano Fibres based Nonwoven Composites: A Review. Mod Chem Appl 5: 206. doi: 10.4172/2329-6798.1000206

Page 10 of 1

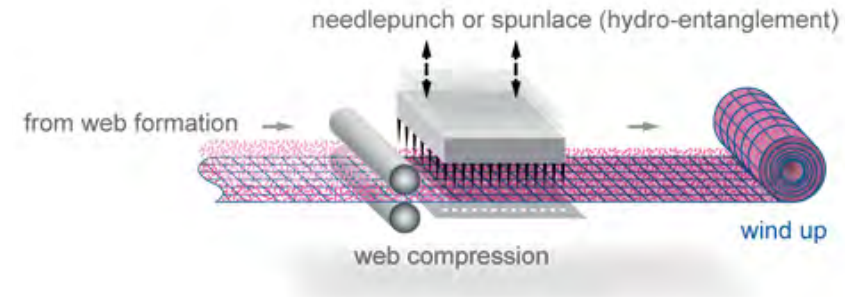

Figure 25: Mechanical bonding process.

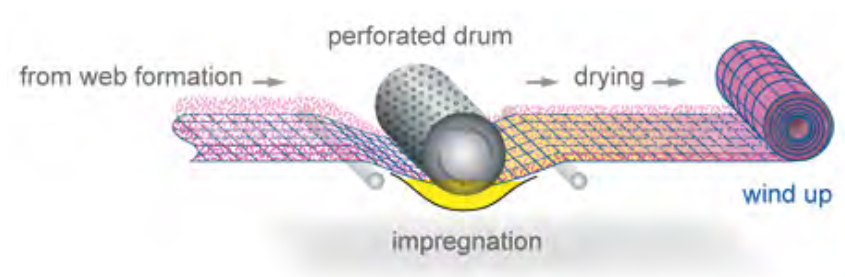

Figure 26: Chemical bonding process.

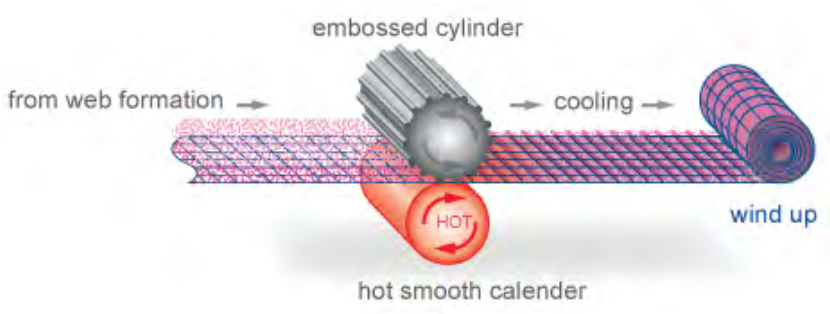

Figure 27: Thermal bonding process.

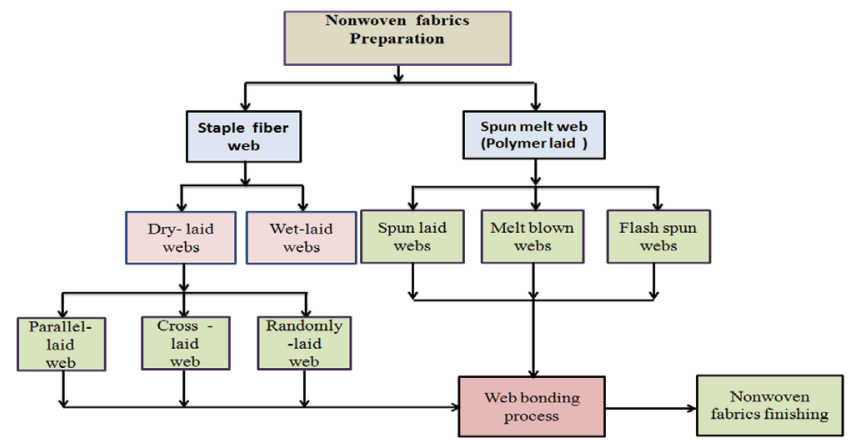

Figure 28: Flow chart for preparation of nonwoven fabrics through various processes.

\section{References}

1. Dubrovski PD, Cebasek PF (2005) Analysis of the mechanical properties of woven and nonwoven fabrics as an integral part of compound fabrics. Fibres and Textiles in Eastern Europe 13: 50-53.

2. Pourdeyhimi B, Ramanathan R, Dent $R$ (1996) Measuring fiber orientation in nonwovens Part I: simulation. Textile Research Journal 66: 713-722.

3. Liao T, Adanur S, Drean JY (1997) Predicting the mechanical properties of nonwoven geotextiles with the finite element method. Textile Research Journal 67: 753-760

4. Tejyan S, Patnaik A, Singh T (2013) Effect of Fibre Weight Percentage on Thermo-Mechanical Properties of Needle punched Nonwoven Reinforced Polymer Composites. International Journal of Research in Mechanical Engineering \& Technology 3: 41-44
5. Wang $Y$ (1999) Effect of consolidation method on the mechanical properties of nonwoven fabric reinforced composites. Applied Composite Materials 6: 19-34.

6. Wang Y, Li J (1995) Properties of composites reinforced with E-glass nonwoven fabrics. Journal of advanced materials 26: 28-34

7. Abdennadher A (2015) Natural Fiber Reinforced Polypropylene Injection Process Micro structure and Properties.

8. Albrecht W, Fuchs H, Kittelmann W (2006) Nonwoven fabrics: raw materials manufacture applications characteristics testing processes.

9. Maldas D, Kokta BV (1995) Composite molded products based on recycled thermoplastics and waste cellulosics II Kenaf fiber-recycled PE composites. Journal of reinforced plastics and composites 14: 458-470.

10. Joseph PV, Joseph K, Thomas S (1999) Effect of processing variables on the mechanical properties of sisal-fiber-reinforced polypropylene composites Composites science and Technology 59: 1625-1640.

11. Joseph K, Toledo FRD, James B, Thomas S (1999) A review on sisa fiber reinforced polymer composites. Brazilian Journal of Agricultural and Environmental Engineering 3: 367-379.

12. Bank LC, Gentry TR, Barkatt A (1995) Accelerated test methods to determine the long-term behavior of FRP composite structures: environmental effects. Journal of Reinforced Plastics and Composites 14: 559-587.

13. Rowell RM, Sanadi A Jacobson R, Caulfield D (1999) Properties of kenaf/ polypropylene composites. Kenaf Properties Processing and Products 381-392.

14. Mishra S, Misra M, Tripathy SS, Nayak SK, Mohanty AK, et al. (2001) Potentiality of pineapple leaf fibre as reinforcement in PALF-polyester composite: Surface modification and mechanical performance. Journal of Reinforced Plastics and Composites 20: 321-334.

15. Mohanty S, Verma SK, Nayak SK (2006) Dynamic mechanical and thermal properties of MAPE treated jute/HDPE composites. Composites Science and Technology 66: 538-547.

16. Pothan LA, Oommen Z, Thomas S (2003) Dynamic mechanical analysis of banana fiber reinforced polyester composites. Composites Science and Technology 63: 283-293.

17. Kamel S (2004) Preparation and properties of composites made from rice straw and poly (vinyl chloride) (PVC). Polymers for advanced technologies 15: 612-616.

18. Bismarck A (2001) Surface characterization of natural fibers surface properties and the water up-take behavior of modified sisal and coir fibers. Green chemistry 3: 100-107.

19. Velmurugan R, Manikandan V (2007) Mechanical properties of palmyra/glass fiber hybrid composites. Composites Part A: applied science and manufacturing 38: 2216-2226.

20. George J (1993) Influence of short pineapple fiber on the viscoelastic properties of low-density polyethylene. Materials Letters 18: 163-170.

21. Satyanarayana KG, Sukumaran K, Mukherjee PS (1990) Natural fibre-polymer composites. Cement and Concrete composites 12: 117-136.

22. Bledzki AK, Reihmane S, Gassan J (1996) Properties and modification methods for vegetable fibers for natural fiber composites. Journal of Applied Polymer Science 59: 1329-1336.

23. Sengupta S, Chattopadhyay SN, Samajpati S, Day A (2008) Use of jute needlepunched nonwoven fabric as reinforcement in composite. Indian J. Fib. Textile Res 33: $37-44$

24. Horrocks AR, Anand SC (2000) Handbook of Technical Textiles. Woodhead Publ.

25. Dubrovski PD, Ziberna SM (1995) The connection between woven fabric construction parameters and air permeability. Fibres and Textiles in Eastern Europe 3: 37-41.

26. Purane SV, Panigrahi NR (2007) Microfibres microfilaments and their applications. AUTEX Research Journal 7: 148-158.

27. Mano JF (2004) Bioinert biodegradable and injectable polymeric matrix composites for hard tissue replacement: state of the art and recent developments. Composites Science and Technology 64: 789-817.

28. Avella M (2000) Preparation and characterisation of compatibilised polycaprolactone/starch composites. Polymer 41: 3875-3881.

29. Huang ZM, Zhang YZ, Kotaki M, Ramakrishna S (2003) A review on polymer nanofibers by electrospinning and their applications in nanocomposites. Composites science and technology 63: 2223-2253. 
30. Wei Q, Wang Y, Yang Q, Yu L (2007) Functionalization of textile materials by plasma enhanced modification. Journal of industrial textiles 36: 301-309.

31. Wakida T, Seiji T (1996) Surface modification of fibre and polymeric materials by discharge treatment and its application to textile processing. Indian Journa of Fibre and Textile Research 21: 69-78.

32. Fabrics produced by these systems are referred to as dry laid nonwovens and carry terms such as "garnetted", "carded" and "air laid".

33. Hutten IM (2007) Handbook of nonwoven filter media. Elsevier.

34. Ghosh AK, Rakshit SK, Talukdar MK (1994) Potentiality of cotton nonwoven fabrics. Indian Journal of Fibre \& Textile Research 19: 224-227.

35. Leon AL (2016) Efficient technical solution for recycling textile materials by manufacturing nonwoven geotextiles. IOP Conference Series Materials Science and Engineering 145: 1-7.

36. Nonwoven Fabrics Technology.

37. Conwed Plastics (2016) Minneapolis, MN 55414, ISO 9001:2008.

38. Atul D, Kamath MG, Raghavendra RH (2004) Haoming Rong \& Ramaiah Kotra Wet-laid nonwovens.

39. Jirsák O, Larry C (1999) Wadsworth. Nonwoven textiles. Carolina Academic Press, USA.

40. EDANA Avenue Herrmann Debroux 46-B-1160, Brussels, Belgium.

41. Fibre to Fabric (2016).

42. NPTEL (2016) A Project funded by MHRD Government of India.

43. Rasel AL (2016) Breaker Carding Machine.

44. Silva E (2010) Hydroentangling Literature Review, pp: 1-10.

45. Malkan SR, Larry C (1992) Wadsworth: A review on spun bond technology. Part II INB Nonwovens 4: 24-33.

46. A\&L Simonyan (2016) German 1040724 Hilden Germany.

47. Ya L, Rouxi C, Juan L (2014) Comparison between electrospun and Bubbfilspun Polyether sulfone fibers. Materia (Rio de Janeiro) 19: 363-369.
48. Erben $J$ (2014) 3D micro-nano fibrous scaffold prepared by melt blown in combination with electrospinning for the bone tissue engineering.

49. Hejazi $F$ (2016) Novel class of collector in electrospinning device for the fabrication of $3 \mathrm{D}$ nanofibrous structure for large defect load-bearing tissue engineering application. Journal of Biomedical Materials Research Part A.

50. Sarac MF, Anderson BD, Pearce RC (2013) Airbrushed Nickel Nanoparticles for Large-Area Growth of Vertically Aligned Carbon Nanofibers on Metal (Al, $\mathrm{Cu}, \mathrm{Ti})$ Surfaces. ACS applied materials and interfaces 5: 8955-8960.

51. Denn MM (1980) Continuous drawing of liquids to form fibers. Annual Review of Fluid Mechanics 12: 365-387.

52. Ramakrishna S, Fujihara K, Teo WE, Lim TC (2005) An introduction to electrospinning and nanofibers 90: 396.

53. Ellison CJ, Phatak A, Giles DW, Macosko CW (2007) Melt blown nanofibers: Fiber diameter distributions and onset of fiber breakup. Polymer 48: 3306-3316.

54. Grafe T, Graham K (2003) Polymeric nanofibers and nanofiber webs: a new class of nonwovens. Nonwoven Technol Rev 12: 51-55.

55. Jirsák O, Dao TA (2009) Production properties and end-uses of nanofibers Nanotechnology in Construction 3: 95-99.

56. Feng L, Li S, Li H, Zhai J, Song Y (2002) Super-hydrophobic surface of aligned polyacrylonitrile nanofibers. Angewandte Chemie 41: 1211-1223.

57. Behrens AM, Casey BJ, Sikorski MJ (2014) In situ deposition of PLGA nanofibers via solution blow spinning. ACS Macro Letters 3: 249-254.

58. Tokarev A, Trotsenko O, Griffiths IM, Stone HA (2015) Magneto spinning of Nano-and Microfibers. Advanced Materials 27: 3560-3565.

59. Donald I (2015) Nano Focus: Magnetic ferrofluid key to new take on spinning polymer fibers. MRS Bulletin 40: 624.

60. Wang $Y$ (1999) Effect of consolidation method on the mechanical properties of nonwoven fabric reinforced composites. Applied Composite Materials 6 : 19-34.

61. Patnaik A, Tejyan S (2012) A Taguchi approach for investigation of solid particle erosion response of needle-punched nonwoven reinforced polymer composites. Journal of Industrial Textiles 43: 458-480. 